\title{
CINTA MENYEMBUHKAN PENYAKIT HATI \\ Sebuah Analisa Cinta menurut Ibnu Taymiyya dan Implikasinya bagi Dialog Islam-Kristen
}

Yan O. Kalampung vian.pemimpi@gmail.com

Abstract. Ibn Taymiyya as one of Syaikul Islam (Islamic Expert) and Mujaddid (Revolutioner) frequently cited by extrimist in Islam. This fact cannot have a good correlation with his long life works that also talks about love. When the writings about love is cited also, the other side of Ibn Taymiyya can be seen as a basis from Islamic-Christian dialogue. This paper is examines the writings of Ibn Taymiyya that talks about love. To seen his concept clearly, $i$ will compare it with the concept of love in Sufism and also seeks the similarity and differences between them to see its influences in Ibn Taymiyya's thought. I will try to see The concept of love from Ibn Taymiyya as a basis for dialogue, eventhough many other writings from him is also cited to support the extrimist concept.

Keywords : Ibn Taymiyya, Love, Sufism, Islam-Christian dialogue.

Abstrak. Ibn Taymiyya sebagai salah satu Syaikul Islam (Ahli Islam) dan Mujaddid (Revolusi) sering dikutip oleh extrimist dalam Islam. Fakta ini tidak dapat memiliki korelasi yang baik dengan karya-karya panjang umurnya yang juga berbicara tentang cinta. Ketika tulisantulisan tentang cinta dikutip juga, sisi lain Ibnu Taimiyah dapat dilihat sebagai dasar dari dialog Islam-Kristen. Makalah ini membahas tulisan-tulisan Ibnu Taimiyah yang berbicara tentang cinta. Untuk melihat konsepnya dengan jelas, saya akan membandingkannya dengan konsep cinta dalam Sufisme dan juga mencari kesamaan dan perbedaan di antara mereka untuk melihat pengaruhnya dalam pemikiran Ibnu Taimiyya. Saya akan mencoba untuk melihat konsep cinta dari Ibnu Taimiyah sebagai dasar untuk dialog, meskipun banyak tulisan lain darinya juga dikutip untuk mendukung konsep extrimist.

Kata kunci: Ibn Taymiyya, Cinta, Sufisme, dialog Islam-Kristen. 


\section{Pendahuluan}

Ibnu Taymiyya adalah salah satu tokoh berpengaruh di dunia Islam. Ia yang juga dikenal sebagai Syaikul Islam (orang yang ahli dalam hal agama Islam), merupakan tokoh yang dimasukkan sebagai sosok Mujaddid (pembaharu) dalam ajaran Islam. Pemikirannya sering disebut-sebut sebagai bibit awal dari gerakan Wahabi dan gerakan-gerakan Ekstrim Islam lainnya yang punya kecenderungan untuk menggunakan kekerasan dalam menyelesaikan persoalan. Bahkan ada tokoh yang menyebut ia juga dijuluki sebagai bapak fundamentalisme Islam pada jaman modern, seperti Ribut Karyono yang juga mengungkapkan bahwa Ibnu Taymiyya termasuk sosok yang memunculkan gerakan fundamentalisme. ${ }^{1}$ Pengaruhnya dalam hal yang demikian masih ada hingga sekarang, khususnya gerakan wahabi di Arab Saudi, Ikhwanul Muslimin di Mesir hingga gerakan ekstremis kontemporer Osama bin Laden. ${ }^{2}$

1 . Ribut Karyono, Fundamentalisme dalam Kristen - Islam, (Yogyakarta : Kalika, 2003) h. 62-65.

2. Hendropriyono, Terorisme Fundamentalis Kristen, Yahudi, Islam, , (Jakarta : Penerbit Buku Kompas, 2009) h. 174.
Yahya Michot, seorang pemikir Islam kontemporer mengindikasikan pengaruh dari Ibnu Taymiyya sekarang dengan menyebutnya telah menjadi semacam "bapak pendahulu" dari AlQaeda. Itu nyata dari konsep pengkategorian dunia ke dalam 3 wilayah berbeda yang dianut oleh Al-Qaeda. ${ }^{3}$ Selain itu, juga harus diakui bahwa pemikiran dari Ibnu Taymiyya juga terbilang "keras" terutama dalam hal hubungan dengan agama yang lain. Salah bukunya yang terkenal, (Al Jawab al sahih li man badal Din Al-Masih - Arab.) Answering those who Altered Religion of Jesus Christ, meringkas pandangannya tersebut, sesuai dengan judulnya, Ibnu Taymiyya berargumen bahwa orang Yahudi dan Kristen sudah keliru memahami Yesus Kristus. Dalam buku tersebut juga ia mengemukakan berbagai bentuk pembelaannya terhadap Muhammad yang ditolak oleh orang Kristen dan Yahudi. ${ }^{4}$ Hizbut Tahrir Indonesia (HTI), mengambil inspirasi dari pemikiran Taymiyya mengenai

\footnotetext{
3. Yahya Michot, The Princeton Encyclopedia of Islamic Political Thought. (Princeton University Press, 2012) h. 238-241.

${ }^{4}$. Ibn Taymiyya, Answering those who altered Religion of Jesus Christ, terj. Bayan Translation Service (Umm Al-Qura) h. xviii.
} 
pentingnya menegakkan syariat Islam secara formal, dalam situs resmi mereka menulis "Ibnu Taymiyah menambahkan, "Wajib diketahui manusia bahwa adanya wilayatul amr (pemerintah) bagi manusia adalah kewajiban yang paling agung dalam agama. Bahkan tidak tegak agama dan juga persoalan dunia tanpanya (pemerintahan)." 8 Dengan demikian kewajiban menegakkan khilafah sebagai metode menerapkan syariat Islam secara formal merupakan kewajiban bagi sleuruh kaum muslim."5 Di atas semua itu, walaupun kenyataanya ia tidak secara langsung menyarankan gerakan-gerakan yang punya kecenderungan seperti kelompok-kelompok yang telah disebutkan tadi, tapi paling tidak gerakangerakan tersebut terinspirasi dari pemikiran-pemikiran salah satu Shaykh besar Islam ini.

Pengaruh-pengaruh yang muncul dari pemikiran dan tulisannya seperti demikian kemudian membuat saya jadi tertarik ketika pada kenyataannya Ibnu Taymiyya sebenarnya memiliki tulisan yang terbilang "lembut" untuk kemudian diteliti lebih lanjut dan dikembangkan.

\footnotetext{
${ }^{5}$ http://hizbut-tahrir.or.id/2007/11/06/pandanganulama-tentang-wajibnya-khilafah/, diakses 03Juli-2015
}

Salah satu pemikiran tersebut adalah pemikirannya tentang konsep "Cinta”. Hal yang satu ini menjadi sesuatu yang menarik untuk dibicarakan di tengah kecenderungan-kecenderungan pemikirannya yang dipergunakan untuk mensahkan perilaku-perilaku kekerasan dari kelompok-kelompok Islam garis keras. Ini kemudian harapannya bisa menjadi sumbangan yang berharga bagi dialog Islam-Kristen. Karena yang diperhatikan selama ini justru pemikiran dari Ibnu Taymiyya yang seperti diuraikan sebelumnya, tapi pada kenyataannya memiliki teks-teks yang mendukung dialog yang lebih sehat dengan agama lain. Bagaimana sesungguhnya pemikiran Ibnu Taymiyya tentang Cinta? Ini menjadi pertanyaan utama dari tulisan ini yang akan coba dijawab. Untuk meneliti hal tersebut saya menggunakan perspektif komparasi. Itu artinya saya akan membandingkan pemikiran Ibnu Taymiyya dengan pemikiran-pemikiran yang lain, agar menjadi jelas bagaimana sesungguhnya konsep Cinta darinya. Untuk meneliti konsep tersebut saya akan membandingkannya dengan konsep Cinta 
dari Sufi ${ }^{6}$ secara umum dan secara khusus salah satu tokoh Sufi yaitu Jalaludin Rumi. Memilih kedua hal ini mungkin menimbulkan reaksi, bukankah justru Ibnu Taymiyya adalah orang yang dengan keras mengkritik pemikiran-pemikiran Sufi semasa ia hidup? Pertanyaan seperti ini mungkin muncul dari orang yang sudah mengetahui latar belakang dari Taymiyya. Di atas semua itu, alasan yang bisa diutarakan mengenai hal ini adalah karena Sufi secara khusus dalam Islam yang banyak berbicara tentang Cinta, sehingga walaupun memang banyak dikritik oleh Taymiyya tapi sekiranya ditemukan perbedaan dan persamaan dari antara mereka maka akan menjadi hal yang menarik. Bagaimana seseorang yang sering mengkritik justru memiliki suatu titik temu dengan yang dikritik.

Dalam kenyataannya seperti dikatakan oleh Abdul Haq Ansari7 bahwa

${ }^{6}$ Pengertian populer dari Sufi diambil dari akar kata Bahasa Arab yang berarti “murni ( $s a f a$ '). kalau ditarik pengertian dari situ maka yang disebut Tasawuf adalah jalan untuk mencapai kemurnian dan Sufi adalah orang menempuh jalan menuju kemurnian tersebut. Lih. Al Qusayri, Risalah Sufi, terj. Ahsin Muhammad, (Bandung :

Penerbit Pustaka, 1994) h. 288.

7. Adul Haq Ansari, Ibn Taymiyah's Criticism of Sufism, dalam Islam and Modern Age, Vol. XV No. 3 Agustus 1984, h. 147. perlu disadari bahwa sejak awal Ibnu Taymiyya tidak menolak Sufisme seutuhnya, itu adalah gambaran yang selama ini dibangun oleh penulis-penulis barat yang membangun gambaran mengenai Taymiyya yang mati-matian melawan Sufi dan tidak melihat tempat bagi mereka di dalam Islam. Memang satu waktu ia mengatakan hal-hal yang menyakitkan tentang Sufi tapi secara umum memiliki simpati terhadap mereka. Pada dasarnya ia tidak menerima pandangan yang menolak Sufi karena bagi dia itu adalah hal yang keliru, yang perlu diterima dari Sufi menurutnya adalah sejauh Sufi sesuai dengan Qur'an dan Sunnah. ${ }^{8}$ Maka Berdasarkan hal yang telah dijelaskan tadi dalam tulisan ini saya pertama-tama akan menjelaskan pandangan dari Sufi secara umum tentang Cinta dan secara khusus konsep Cinta dari Rumi. Setelah itu saya akan masuk ke dalam pemikiran Ibnu Taymiyya tentang Cinta dalam perbandingan dengan kedua pemikiran tadi dengan harapan semakin memperjelas konsep Cinta darinya. Kemudian dari konsep tersebut, saya akan menarik implikasinya bagi dialog IslamKristen yang lebih baik dari Ibnu Taymiyya

\footnotetext{
${ }^{8}$. Ibid, h. 147.
} 
yang pemikirannya banyak dipakai oleh kaum ekstrimis. Tulisan singkat ini harapannya bisa memberi pandangan yang berimbang tentang pemikiran Ibnu Taymiyya yang punya pengaruh besar tersebut.

\section{Cinta dalam Sufi}

Joseph E. B. Lumbard dengan tepat mengatakan bahwa tema tentang Cinta sudah menjadi komponen penting dalam Sufisme sejak abad kedua hingga kini dan sudah begitu banyak pemikir yang sudah menguraikan pandangannya tentang hal ini. ${ }^{9}$ Pada kenyataannya memang tak dapat disangkal bahwa Sufi menaruh perhatian khusus terhadap Cinta. Titus Burckhardt juga mengatakan hal yang senada bahwa sudah menjadi salah satu karakteristik Sufisme yaitu ekspresi-ekspresinya sering berpegang pada keseimbangan antara Cinta dan pengetahuan. Suatu bentuk ekspresi emosional lebih mudah memadukan sikap keagamaan yang merupakan titik awal setiap kehidupan kehidupan kerohanian Islam. Menurutnya, Bahasa Cinta memang memungkinkannya

\footnotetext{
9 . Joseph E. B. Lumbard, From Hubb to 'Ishq : The Development of Love in Early Sufism, dalam Journal of Islamic Studies, Volume 18 Number 3 September 2007, h. 345.
}

untuk menegaskan kebenaran-kebenaran paling dalam tanpa masuk ke dalam konflik dengan teologi dogmatis. ${ }^{10}$

Al-Qusayri dalam bagian awal Risalahnya mengenai Cinta (Muhabbah) mengatakan bahwa memang para ulama seringkali mengartikan Cinta sebagai hasrat dan keinginan. Tapi karena Cinta adalah berasal dari Allah maka hasrat manusiawi tidak akan bisa disematkan kepada Allah. Jika disematkan kepada hamba yang dikaruniai Cinta oleh Allah maka mungkin itu agak cocok, tapi yang dimaksudkan oleh Kaum Sufi melampaui pengertian yang dikatakan oleh para ulama tadi. ${ }^{11}$ Pengertian yang singkat dan jelas tentang Cinta menurut Sufi disampaikan oleh Al-Junayd ${ }^{12}$, bahwa Cinta adalah kecenderungan hati, dalam arti bahwa hati seseorang itu selalu condong kepada Allah. Selain itu, Cinta menurutnya adalah penyesuaian, dalam arti kepatuhan kepada Tuhan secara penuh dan berusaha dengan sungguh-

\footnotetext{
10. Titus Burckhardt, Mengenal Ajaran Sufi, terj. Azyumardi Azra, (Jakarta : Pustaka Jaya, 1984) h. 38.

11. Al Qusayri, Risalah Sufi, terj. Ahsin Muhammad, (Bandung : Penerbit Pustaka, 1994) h. 322.

12. Al Kalabdzi, Ajaran Kaum Sufi, terj. Rahmani Astuti, (Bandung : Penerbit Mizan, 1985) h. 137.
} 
sunguh agar dirinya dapat sesuai dengan segala yang difirmankan olehNya.

Pengertian tersebut dalam beberapa hal bersangkut-paut dengan pertanyaan yang ditulis Al Qusayri tentang apakah Cinta dalam sufi memang menyangkut kenikmatan yang dialami oleh seseorang terhadap Tuhan. Jawaban dari pertanyaan ini adalah bukan. Penjelasan tentang jawaban ini kemudian memperlihatkan makna yang lebih luas jika dibandingkan dengan yang dikatakan oleh Al Junayd tadi mengenai penyesuaian, Jawabannya menurut Qusayri, ketika seseorang itu mencintai Tuhan, maka dirinya musnah dihadapanNya sehingga yang ada hanyalah Tuhan dalam dirinya. Seseorang itu digambarkan sebagai si pecinta yang musnah dihadapan sang Kekasihnya. Ini menegaskan bahwa dalam relasi Cinta seseorang dengan Tuhan tidak ada kenikmatan secara manusiawi. ${ }^{13}$ Lebih lanjut, Al Kabadzi memberi penjelasan tambahan tentang itu, bahwa dengan Cinta seseorang kepada Tuhan maka seseorang tersebut akan mengalami kesusahan karena tidak sesuatupun yang layak untuknya selain daripada Tuhan. Maksud dengan perkataan tersebut yaitu

\footnotetext{
${ }^{13}$. Al Qusayri, Risalah Sufi, h. 324
}

tidak ada hal lain yang layak untuk dirinya selain Tuhan, diartikan bahwa tidak sesuatupun bagian dirinya yang tinggal, yang memungkinkannya melakukan halhal lain, atau menaruh perhatian pada kondisi-kondisi material. Lebih lanjut AlKabadzi kemudian mengutip pandangan dari Ibn Abd al-Shamad yang berkata bahwa Cinta adalah yang mendatangkan kebutaan dan ketulian; Cinta membutakan segalanya kecuali terhadap Yang dicintainya, sehingga orang itu tidak melihat apapun kecuali Dia. Ungkapanungkapan ini menampakkah pengertian Cinta dalam Sufi bahwa ketika seseorang itu mengalami Cinta kepada Tuhan maka dirinya betul-betul berfokus kepada Tuhan sehingga tidak ada tempat lain lagi dalam dirinya selain untuk Tuhan.

Cinta yang diarahkan kepada Tuhan juga memberi konsekuensi untuk hubungan seseorang dengan sesamanya. Hal mendasar yang perlu dipahami oleh seseorang ketika coba mendalami Cinta kepada Tuhan dijelaskan oleh Al-Junayd, "Cinta adalah seorang pelayan yang meninggalkan jiwanya dan melekatkan dirinya pada dzikir kepada Tuhannya, mengukuhkan diri dalam melaksanakan perintah-perintah Tuhan dengan 
kesadaran yang terus menerus akan Dia dalam hatinya."14 Kesadaran akan Tuhan karena Cinta kemudian menuntun kepada kesadaran akan sesama. Seperti nampak dalam pandangan Syaikh $\mathrm{Abu}$ ' Ali adDaqqaq yang mengatakan bahwa cinta berarti lebih mengutamakan orang lain daripada diri sendiri. Ia kemudian memberi contoh isteri Potiphar yang menyesali perbuatannya kepada Yusuf dan mengakui perbuatannya, "Akulah yang menggodanya untuk menundukkan dirinya, dan sesungguhnya dia termasuk orang-orang benar"15 Dalam penjelasan ini menampakkan bagaimana dimensi Cinta kepada Tuhan juga memberi dampak pada bagaimana berelasi dengan sesama. Penyesalan dan pengakuan dari isteri Potiphar juga memperlihatkan bahwa Cinta kepada Allah yang kemudian berdampak kepada sesama, membawa pemurnian kepada diri isteri Potiphar seperti dikatakan oleh Al-Qusayri bahwa mula-mula ia menuduh Yusuf telah berbuat jahat, tetapi akhirnya dia menyalahkan dirinya sendiri atas pengkhianatannya itu. Isteri Potiphar yang semula terkontaminasi dengan perbuatan

\footnotetext{
14 . Ibid, h. 334

${ }^{15}$. Ibid, h. 335
}

buruk kemudian karena Cinta memurnikan dirinya sendiri dengan mengakui kesalahannya.

Hal yang tidak mengherankan lagi sebagai bagian dari Sufi dan begitu terkenal sebagai salah tokoh besarnya, Rumi (1207-1273) juga berbicara tentang Cinta. Bahkan pandangannya juga seringkali diringkas dengan Jalan Cinta (Path of Love). Dalam puisi-puisinya ia seringkali menggambar orang yang beriman itu sebagai seorang pecinta. Mungkin ini juga yang menjadi alasan mengapa tulisannya seringkali menarik begitu banyak orang yang mencari sumber spiritual dari hampir semua agama di dunia, untuk ratusan tahun. ${ }^{16}$

Gambaran Rumi tentang Allah selalu personal dan menggambarkan relasi Cinta, sehingga dibanding menggunakan ungkapan maskulin seperti Allah, ia lebih cenderung menggunakan ungkapan "Yang Tercinta". Kalau dalam ulasan mengenai Sufi pada bagian sebelumnya menggambarkan bagaimana seseorang yang sedang mencintai itu begitu terfokus pada Yang Dicintai maka Rumi pun demikian. Dalam salah satu tulisannya

\footnotetext{
${ }^{16}$. A. J. Arberry, Introduction, dalam Rumi, Fihi ma Fihi, terj. A. J. Arberry, (Iowa : Omphaloskepsi, 2000) h. vi.
} 
yang terkenal yaitu Fihi ma Fihii, Rumi mengatakan bahwa ketika seseorang itu semakin mengikuti keinginan penguasa (Raja) dan dunia, maka ia semakin menjadi jauh dari Yang Tercinta, "Semakin kamu berdamai dengan orang-orang dunia, maka semakin jauh pula Yang Tercinta darimu."17

Rumi memahami bahwa Cinta mensyaratkan siapa yang terutama, hanya satu yang bisa menempatkan tempat yang khusus dalam diri sang pecinta entah itu Allah maupun dunia. Yang benar seperti yang digambarkan oleh perkataan Rumi tadi, bahwa Yang Tercinta akan mendekat kalau sang pecinta tidak memberi tempat bagi yang lain.

Semakin mengelaborasi pandangan tentang Cinta, Rumi kemudian menggambarkan dalam salah satu puisinya, bahwa Cinta adalah tanda seseorang hidup, "Di Mata Tuhan, dia yang tidak memiliki warna Cinta, tiada lain adalah kayu dan Batu"18. Ini semakin mempertegaskan bahwa dalam ajaran spiritualnya, ia kemudian memberi posisi

\footnotetext{
17. Jallaludin Rumi, Fihi ma Fihi, terj. A. J. Arberry,(Iowa : Omphaloskepsi, 2000) h. 16-17.

${ }^{18}$. William Chittick, Jalan Cinta Sang Sufi : Ajaranajaran Spiritual Jallaludin Rumi, (Yogyakarta : Kalam, 2000) h. 251.
}

yang penting bagi pembicaraan tentang Cinta, sehingga tidak mengherankan kalau dalam puisinya yang lain ia kemudian semakin mendukung hal ini, "Pilihlah Cinta, Cinta ! Tanpa manisnya Cinta hidup adalah beban"19, nampak dalam puisinya ini bahwa Cinta bukan hanya sekedar sebuah slogan yang dipakai untuk menggambarkan relasi antara manusia dengan Tuhan dan tanda bahwa seseorang itu hidup, tapi juga harus dipilih menjadi jalan hidup, agar hidup yang dijalani itu bisa seperti tanpa beban. Kalau dikaitkan dengan pandangan mengenai Cinta dalam Sufi, maka pandangannya ini semakin mempertegaskan pandangan yang ada bahwa dalam Cinta seseorang tidak akan memikirkan yang lain, selain yang dicintai itu dan juga akan membawa anugerah seperti yang digambarkan Rumi tadi.

Sama seperti para Sufi, Rumi-pun memahami bahwa Cinta hanya ditujukan kepada Tuhan saja, William Chittick menyebutnya sebagai "cinta sejati/ ishq haqiqi". Namun karena Cinta Tuhan itu menyebar ke mana-mana dan ke seluruh semesta ini, maka semua Cinta yang ada sebenarnya merupakan perwujudan dari

\footnotetext{
${ }^{19}$. Ibid.
} 
Cinta Tuhan. Menurutnya, ini semua bisa terjadi karena segala-sesuatu adalah pantulan dan bayang-bayangNya. 20 Pemahaman ini jika dielaborasi lebih lanjut, kemudian memberi dampak bahwa semua perbuatan-perbuatan yang memancarkan Cinta juga sebenarnya berasal dari Cinta Tuhan. Bahkan lebih lanjut dikatakan bahwa sebenarnya semua bentuk dunia tidak lain adalah pantulanpantulan realitasnya. Salah satu puisi Rumi meringkas semua ini, "Dunia bagaikan cermin yang memantulkan kesempurnaan Cinta. Oh kawan! Siapakah yang pernah melihat bagian lebih besar dari keseluruhan?"21

Konsekuensi dari pandangan ini adalah jati diri dari seluruh ciptaan adalah Cinta. Jika diperluas lagi, maka Cinta yang seharusnya menjadi landasan bagi seluruh relasi yang seharusnya tercipta di antara ciptaan. Inilah alasan mengapa Rumi begitu merekomendasikan Cinta untuk menjadi pilihan jalan hidup. Karena relasi yang harusnya tercipta di antara seluruh ciptaan adalah relasi Cinta. Annamarie Schimmel menggambarkan dengan tepat aspek relasi ciptaan dari Cinta dengan

\footnotetext{
20 . Ibid, h. 246.

21. Ibid, h. 241
}

mengatakan bahwa "Cinta adalah segalanya, inang dan ayah, paman dari pihak ibu dan paman dari pihak ayah. Bukanlah Cinta yang, meskipun ia itu sendiri tidak berbentuk dan tidak punya tangan, memberi manusia bentuk dan tangan dengan mempersatukan ayah dan ibu dalam permainan cinta?" Singkat cerita, Cintalah yang mempersatukan kita.

\section{Cinta menurut Ibnu Taymiyya}

Sesuatu yang unik dalam pandangan Ibnu Taymiyya adalah bahwa menurutnya Cinta adalah obat bagi penyakit hati. Yang nampak dalam tulisannya, bahwa seringkali seseorang itu merasakan dan mengikuti rasa Cinta (Ishq') yang kemudian merusak dirinya sendiri, inilah yang menjadi penyakit hati. Hal-hal seperti iri hati, dengki dan keserakahan dan kebencian selalu menjadi perasaan yang membawa orang yang memilikinya masuk ke dalam hal yang buruk. ${ }^{22}$ Dalam konteks nasihatnya kepada orang-orang Islam dalam membangun masyarakat, ia juga mengungkap bahwa seseorang itu tidak boleh serakah dan

\footnotetext{
${ }^{22}$ Ibn Taymiyya, Against Extrimisms, terj. Yahya Michot, (Beirut, Libanon : Albouraq, 2012) h. 106.
} 
meminta jabatan untuk dirinya,. Yang harus dilakukan seseorang ketika diperhadapkan dengan jabatan dalam suatu masyarakat adalah menerima kalau ditawarkan bukannya meminta atau mencari.

Ibnu Taymiyya sadar bahwa ketika seseorang merasakan cinta terhadap sesuatu, maka ia akan mengupayakan segala cara untuk mendapatkannya. Ini kemudian bisa diaplikasikan untuk semua orang di semua tingkatan masyarakat. Cinta yang menuntun seseorang tersebut untuk melakukan hal yang jahat seperti mencelakai orang lain agar tidak mendapatkan yang dicintainya, maka itu cinta berdasarkan rasa iri yang perlu dihindari. ${ }^{23}$ Namun demikian jika seseorang menahan diri (wara') dari cinta tersebut, maka pengampunan bisa menjadi miliknya, dan Allah menyediakan tempat yang khusus baginya. ${ }^{24}$ Ini menunjukkan bahwa seseorang bisa menghindari penyakit hati tersebut pada awalnya bisa dengan dengan menahan diri.

Singkat kata, segala sesuatu keinginan, kehendak atau hasrat yang

\footnotetext{
${ }^{23}$ Ibid, h. 115-116.

${ }^{24}$ Ibn Taymiyya, Expounds on Islam, terj. Muhammad 'Abdul-Haqq Ansari, (2000) h. 430.
}

menggebu-gebu terhadap berbagai hal yang kemudian membawa pemiliknya terjebak dalam hal yang buruk adalah penyakit hati. Hal-hal seperti itu pada awalnya memang menjadi penyakit hati, namun tidak dapat dipungkiri juga nantinya akan berakibat pada tubuh. Bagi Ibnu Taymiyya, hanya Cinta (Mahabba) yang bisa menyembuhkan penyakit tersebut. Jika lebih spesifik lagi, maka Cinta kepada Allah yang bisa menyembuhkan. Di sini nampak pandangan dari Taymiyya mirip dengan pandangan Sufi dan Rumi tadi, dengan penekanan pada Cinta akan Allah yang menyembuhkan namun juga memurnikan, sehingga membuat dalam hati seseorang itu tidak ada lain selain Allah. ${ }^{25}$ Hal itu juga nampak dalam pandangan Taymiyya bahwa asal (fitra) sesungguhnya dari seseorang itu adalah Cinta kepada Allah, sehingga sebenarnya proses pemurnian harus menggiring seseorang untuk memulihkan Cintanya kepada Allah. ${ }^{26}$ Cinta kepada Allah yang penting dan terutama dan itu harusnya yang menjadi fondasi kehidupan.

\footnotetext{
${ }^{25}$ Ibn Taymiyya, Diseases of The Heart and their Cures, terj. Abu Rumaysah, (Birmingham : Daar Us-Sunnah Publishers) h. 126.

${ }^{26}$ Ibn Taymiyya, Against Extrimisms, h. 116.
} 
Ibnu Taymiyya memberi contoh salah seorang yang sudah terkontaminasi dengan penyakit hati yaitu orang yang sudah begitu mencintai seorang budak sehingga melakukan hal-hal yang melanggar aturan-aturan yang ada. Disini bisa dilihat bahwa penyakit hati adalah juga menyangkut persoalan apakah seseorang taat kepada hukum atau tidak. Dalam hal ini yang dijadikan contoh olehnya adalah Yusuf yang tidak terjerumus ke dalam cinta yang sesat seperti yang ditawarkan oleh Istri Potiphar sehingga Allah memberi gelar kepadanya sebagai sosok hamba yang teladan. ${ }^{27}$

Cinta bagi Ibnu Taymiyya tidak bisa dilepaskan dari dua nilai yang harus dimiliki hati yang lain yaitu, kepercayaan (trust) dan ketulusan (ikhlas). Ketiga terajut dalam jalinan yang indah kalau semuanya itu diramu dalam penyembahan hidup yang sungguh kepada Allah. ${ }^{28}$ Ketiga hal itu jika diperhatikan bersama sebenarnya juga nampak bukan hanya kepada Allah tetapi semua memiliki konsekuensi logis kepada sesama. Telah dijelaskan tadi bahwa salah satu konsekuensi logis dari cinta yang

\footnotetext{
${ }^{27}$ Ibid., h. 119.

${ }^{28}$ Ibn Taymiyya, Expounds on Islam, h. 439.
}

berdasarkan iri kemudian dapat membawa pada perbuatan mencelakai orang lain.

$$
\text { Dimensi horizontal yang }
$$
memperhatikan sesama seperti itu menjadi alasan mengapa Cinta kepada Allah kemudian menjadi penting. Selain hal itu, ketika membicarakan penyembahan yang tulus kepada Allah, seringkali orang Islam menurut Taymiyya hanya terpaku pada persoalan ritual saja. Ketulusan harus juga memberi dampak kepada sesama, dalam hal ini masyarakat. ${ }^{29}$ Orang Islam sering terpaku pada ketulusan dalam melakukan penyembahan, sholat dan puasa sehingga melupakan dimensi ketulusan kepada masyarakat. Ketulusan kepada Tuhan, menurut Taymiyya harus juga membawa keuntungan bagi orang-orang yang ada di sekitarnya. Jadi Cinta yang tulus kepada Allah harus juga membawa dampak positif kepada sesama, seperti yang ada di dalam perkataan Nabi Muhammad, "Hanya tujuh orang yang akan dinaungi Allah pada hari dimana tidak ada naungan lain, selain daripada Allah ; penguasa yang adil, ..., teman-teman yang saling menyayangi dan berkumpul karena alasa Allah, ..., dan

\footnotetext{
${ }^{29}$ Ibid., h. 442.
} 
orang yang memberi sedekah kepada orang lain dengan cara sedemikian rupa hingga tangan kirinya tidak tahu apa yang dilakukan oleh tangan kanannya, ..."30 Jika diperhatikan secara seksama sebenarnya dimensi horizontal dari konsep Cinta Taymiyya, juga menampakkan warna yang sama dengan Sufi dan Rumi. Kalau sufi memperlihatkan bahwa Cinta itu adalah mementingkan orang lain dibanding diri sendiri, Rumi memandang Cinta selalu membawa kehidupan bagi sesama, Taymiyya sendiri melihat bahwa Cinta itu harus selalu membawa dampak positif bagi sesama. Satu hal yang mempersatukan mereka semua adalah bahwa Cinta yang positif terhadap sesama itu, semua bersumber dari Allah. Allah yang merupakan sumber Cinta, mengundang manusia untuk mencintaiNya, kemudian dalam Cinta kepada Allah itu manusia kemudian menjadi berkah bagi sesama.

\section{Implikasi bagi Dialog Islam-Kristen}

Dalam dokumen Interreligius Konsili Vatikan II yang dipersiapkan Maurice Borrmans, dijelaskan bahwa jalan menuju dialog Islam-Kristen pada awalnya

\footnotetext{
${ }^{30}$ Ibid, h. 443.
}

harus dimulai dengan cinta yang bersemi dari penerimaan satu sama lain. ${ }^{31}$ Konsep Cinta menurut Ibnu Taymiyya yang kalau diterapkan untuk konteks dialog antaragama, memberi suatu inspirasi yang agak berbeda. Mirip dengan konsep cinta dari Sufi secara umum dan Rumi, Taymiyya juga menekankan Cinta kepada Allah yang utama. Cinta kepada Allah adalah fitrah sekaligus tempat berpegang agar tidak jadi ke dalam dosa. Ketika jatuh dalam dosa, maka dengan kembali kepada Cinta akan Allah maka itu juga menjadi jalan pemurnian yang paling ampuh.

Konsekuensi dari Cinta akan Allah itu, kemudian seperti telah dijelaskan tadi bahwa itu kemudian membawa dampak positif bagi sesama. Dari perspektif Ibnu Taymiyya, Cinta yang tulus kepada Allah harus membawa keuntungan bukan hanya kepada diri sendiri, tapi juga kepada sesama. Suatu pandangan yang sejalan dengan konsep Cinta Sufi yang menekankan pengorbanan untuk orang yang lain serta Rumi yang memandang Cinta harus selalu membawa kehidupan bagi yang lain di semesta ini. Dalam salah

\footnotetext{
${ }^{31}$ Maurice Borrmans, Interreligious Documents I : Guidelines for Dialogue between Christians and Muslims, terj. R. Marston Speight, (New York : Paulist Press, 1981) h. 31.
} 
satu hadits yang dikutip Ibnu Taymiyya, mengatakan hal yang menarik bahwa yang akan diselamatkan pada akhir zaman salah satunya adalah orang memberi sedekah dengan tangan kiri namun tak diketahui oleh tangan kanan. Ini sama persis dengan salah satu ayat di Injil yang mengatakan bahwa ketika memberi untuk orang lain maka "tangan kiri tidak boleh mengetahui apa yang dilakukan tangan kanan" (Mat. 6:3).

Judowibowo Poerwowidagdo yang membicarakan tentang niatan positif dari kaum Islam yang mengusulkan surat terbuka bagi perdamaian Islam-Kristen yang berjudul : "A Common Word Between Us and You", kemudian mengatakan dasar pemahaman dari upaya tersebut adalah prinsip dari kedua agama tersebut yaitu : kasih kepada Tuhan Yang Maha Esa dan kasih kepada sesama manusia. ${ }^{32}$ Hal ini juga yang nampak dalam Cinta menurut Ibnu Taymiyya, Cinta yang ditujukan kepada Allah kemudian memberi dampak kepada sesama. Atau mungkin saya bisa

\footnotetext{
32 Judowibowo Poerwowidagdo, Membumikan Berita Damai : Kebersamaan dalam Keberagaman, dalam Hendri Wijayatsih, Gunawan Adi Prabowo dan Purwaningtyas Rimukti (ed.), Memahami Kebenaran Yang Lain sebagai Upaya Pembaharuan Hidup Bersama, (Yogyakarta : Taman Pustaka Kristen, 2010) h. 244-245.
}

bahasakan lain dengan mengatakan bahwa Cinta kepada Allah harusnya juga membawa berkah bagi sesama. Cinta dari Ibnu Taymiyya yang menekankan seseorang untuk mengontrol diri dari penyakit hati yang kemudian jika diikuti dapat membawa dampak negatif bagi sesama. Cinta kepada Allah yang murni bias menyembuhkan penyakit hati yang bukan hanya membawa kerugian bagi si pemilik tapi bagi orang lain di sekitarnya. Cinta kepada Allah ini bisa menjadi titik dialog yang baik, karena dengan berfokus pada Cinta akan Allah, orang beriman akan terhindar dari penyakit-penyakit hati yang menghasilkan perilaku yang merugikan orang lain. Menurut saya surat terbuka dari kaum cendekiawan Muslim adalah contoh jelas dari hal ini. Cinta kepada Allah yang murni juga memurnikan sikap kita kepada sesama menjadi sikap yang membawa berkah. Dari perspektif ini, saya pikir dialog yang lebih sehat bisa dibangun. Bukannya dengan memakai pendekatan kekerasan seperti yang dipakai oleh kelompok-kelompok fundamentalis, menurut saya pendekatan Cinta yang lebih efektif untuk membangun perdamaian antara Islam dan Kristen. Dibanding hanya memakai teks-teks yang 
mungkin cukup "keras" dari Ibnu Taymiyya, maka dengan juga memperhatikan teks-teks lain yang lebih "lembut" contohnya yang membicarakan Cinta maka pandangan yang berimbang dan utuh dari Ibnu Taymiyya bisa dibangun. Dari keutuhan tersebut, pemikiran Taymiyya bisa diperhatikan dengan lebih proporsional sesuai dengan konteksnya, dan juga memperhatikan konteks kini dengan kebutuhan akan perdamaian terus ada.

\section{Penutup}

Demikianlah saya sudah memberikan penjelasan mengenai konsep Cinta dari Ibnu Taymiyya yang nyatanya banyak terpengaruh dengan Sufi, terutama penekanannya pada Cinta kepada Allah yang harus juga membawa berkah bagi sesama. Inilah yang kemudian saya jadikan dasar dari dialog Islam-Kristen. Dibanding hanya melihat satu sisi pemikirannya yang kemudian sering dijadikan dasar oleh kaum fundamentalis untuk melakukan pendekatan dengan kekerasan, maka saya mengusulkan mari kita melihat juga teks-teks dari Ibnu Taymiyya yang sebenarnya memberi ruang lebih besar bagi kepedulin terhadap sesama yang juga terwujud dengan dialog yang lebih sehat dan manusiawi.

\section{Bibliografi}

Al Kalabdzi, Ajaran Kaum Sufi, terj. Rahmani Astuti, Bandung : Penerbit Mizan, 1985.

Al Qusayri, Risalah Sufi, terj. Ahsin Muhammad, Bandung : Penerbit Pustaka, 1994.

Borrmans Maurice, Interreligious Documents I : Guidelines for Dialogue between Christians and Muslims, terj. R. Marston Speight, New York : Paulist Press, 1981.

Burckhardt Titus, Mengenal Ajaran Sufi, terj. Azyumardi Azra, Jakarta : Pustaka Jaya, 1984.

Chittick William, Jalan Cinta Sang Sufi : Ajaran-ajaran Spiritual Jallaludin Rumi, Yogyakarta : Kalam, 2000.

Hendropriyono, Terorisme Fundamentalis Kristen, Yahudi, Islam, Jakarta : Penerbit Buku Kompas, 2009.

Karyono Ribut, Fundamentalisme dalam Kristen - Islam, Yogyakarta : Kalika, 2003.

Michot Yahya, The Princeton Encyclopedia of Islamic Political Thought, Princeton University Press, 2012. 
Poerwowidagdo Judowibowo, Membumikan Berita Damai : Kebersamaan dalam Keberagaman, dalam Hendri Wijayatsih, Gunawan Adi Prabowo dan Purwaningtyas Rimukti (ed.), Memahami Kebenaran Yang Lain sebagai Upaya Pembaharuan Hidup Bersama, Yogyakarta : Taman Pustaka Kristen, 2010.

Rumi Jallaludin, Fihi ma Fihi, terj. A. J. Arberry, Iowa : Omphaloskepsi, 2000.

Taymiyya Ibn, Against Extrimisms, terj. Yahya Michot, Beirut, Libanon : Albouraq, 2012.

Taymiyya Ibn, Answering those who altered Religion of Jesus Christ, terj. Bayan Translation Service, Umm Al-Qura.

Taymiyya Ibn, Diseases of The Heart and their Cures, terj. Abu Rumaysah,
Birmingham : Daar Us-Sunnah Publishers

Taymiyya Ibn, Expounds on Islam, terj. Muhammad 'Abdul-Haqq Ansari, 2000.

Ansari Adul Haq, Ibn Taymiyah's Criticism of Sufism, dalam Islam and Modern Age, Vol. XV No. 3 Agustus 1984,

Lumbard Joseph E. B., From Hubb to 'Ishq : The Development of Love in Early Sufism, dalam Journal of Islamic Studies, Volume 18 Number 3 September 2007 
